\title{
IMPLEMENTASI KOMUNIKASI NIRKABEL 433MHZ MENGGUNAKAN APC220 TRANSCEIVER PADA ROBOT MUSIK ANGKLUNG
}

\author{
Rini Handayani1, ${ }^{*}$, Simon Siregar² \\ 1,2 Program Studi D3 Teknik Komputer, Fakultas IImu Terapan, Universitas Telkom \\ (corresponding author) rini.handayani@tass.telkomuniversity.ac.id *)
}

\begin{abstract}
The introduction of a culture which is accompanied by applied technology enables users/tourists to recognize and enjoy performance one of Indonesian traditional musical instruments (in this case: Angklung). To make a sound, Anklung has to vibrate almost all the parts. Angklung, in this case, consists of several units Sarinande melodic angklung which made by Saung Udjo, an anklung maker. These Angklung is played simultaneously as a choir. In this research, how to apply a technology which can imitate the vibratation of several Angklung in accordance to the song being played and integrate the system with the user interface and mechanical drive systems. The 'brain' to imitate and to control the vibration is using a microcontroller ATMega2560. This microcontroller are connected to motor driver to control the movement of the vibration motor and to wireless comunication module to send and receive command and send data. The wireless communication itself, APC 220, is working in frequency of $433 \mathrm{MHz}$, with several option of baudrate and air-rate. A data will be transmitted in the fashion of broadcast from a Personal Computer which work as a master and interface between user and the system to the slave. In the user interface, a Graphical User Interface(GUI) is developed. With this GUI, the users can easely select one of the songs from the playlist and play the songs. After several testing of the system, the system work as designed design.
\end{abstract}

\section{Keyword- Angklung, Microcontroller ATMega2560, Wireless Communication, APC220}

Intisari- Pengenalan budaya yang disertai dengan teknologi terapan memungkinkan pengguna / wisatawan untuk mengenal dan menikmati pertunjukan salah satu alat musik tradisional Indonesia (dalam hal ini: Angklung). Untuk membuat suara, Anklung harus bergetar hampir semua bagiannya. Angklung, dalam hal ini, terdiri dari beberapa unit angklung melodi Sarinande yang dibuat oleh Saung Udjo, pembuat anklung. Angklung ini dimainkan bersamaan sebagai paduan suara. Dalam penelitian ini, bagaimana menerapkan teknologi yang bisa meniru vibratasi beberapa angklung sesuai dengan lagu yang sedang dimainkan dan mengintegrasikan sistem dengan user interface dan sistem penggerak mekanis. 'Otak' untuk meniru dan mengendalikan getaran menggunakan mikrokontroler ATMega2560. Mikrokontroler ini terhubung ke motor driver untuk mengendalikan pergerakan motor getaran dan modul komunikasi nirkabel untuk mengirim dan menerima perintah dan mengirim data. Komunikasi nirkabel itu sendiri, APC 220, bekerja pada frekuensi $433 \mathrm{MHz}$, dengan beberapa pilihan baudrate dan air-rate. Sebuah data akan ditransmisikan dengan cara disiarkan dari Personal Computer yang bekerja sebagai master dan interface antara pengguna dan sistem ke slave. Di antarmuka pengguna, Graphical User Interface (GUI) dikembangkan. Dengan GUI ini, pengguna dapat dengan mudah memilih salah satu lagu dari daftar putar dan memutar lagu. Setelah beberapa pengujian sistem, sistem bekerja seperti desain yang dirancang.

Kata Kunci- Angklung, Mikrokontroler ATMega2560, Komunikasi Nirkabel, APC220

\section{PENDAHULUAN}

Indonesia memiliki banyak objek wisata salah satunya adalah wisata budaya. Kemajemukan budaya Indonesia dapat menjadi daya tarik minat wisatawan domestik maupun mancanegara salah satunya melalui kesenian tradisional. Keutamaan dan nilai positif dari unsur-unsur budaya tertuang mencerminkan kearifan lokal wilayah setempat. Hal ini perlu diadakannya upaya-upaya pelestarian dan pengembangan kesenian tradisional [1]. Kurangnya minat dan wawasan generasi muda dalam mengenal kesenian musik tradisional, tenaga pengajar yang terbatas, dan sulitnya pengadaan instrumen menjadi kendala tersendiri dalam pelestarian kesenian budaya khususnya musik tradisional [2]. Dengan mengkolaborasikan teknologi terapan dengan kesenian budaya khususnya dalam bidang musik diharapkan dapat menjadikan suatu alternatif penyajian pertunjukan.

Teknologi yang diterapkan pada robot musik angklung ini menggunakan topologi master dan slave. Dimana perangkat master bertugas sebagai pemberi perintah utama yang masukannya berasal dari pengguna melalui sebuah antarmuka GUI (Graphical User Interface). Kemudian perintah tersebut diterima oleh perangkat slave melalui mikrokontroler ATMega2560 untuk mengaktifkan motor sebagai penggerak angklung. Angklung yang digunakan pada aplikasi ini terdiri dari dua unit Angklung Melodi Sarinande dari Saung Udjo. Angklung-angklung ini memainkan musik secara bersamaan 
layaknya kor pada paduan suara. (Pada pengembangan berikutnya dapat ditambahkan beberapa unit angklung sejenis maupun berbeda untuk menambahkan harmonisasi suara yang dihasilkan). Jika angklung-angklung ini terhubung dengan kabel tentunya membuat konfigurasi menjadi terbatas.

Untuk itu komunikasi nirkabel digunakan pada sistem ini. Kemudahan instalasi dan efisiensi dari komunikasi nirkabel ini memungkinkan untuk menambahkan atau memperluas topologi dengan lebih mudah [3]. Terlebih lagi, sistem ini ditempatkan pada lokasi yang cenderung lapang dengan sedikit penghalang (lossless) juga memungkinkan sistem berjalan dengan delay propagasi yang sangat minim [4]. Komunikasi nirkabel pada sistem ini digunakan untuk menghubungkan antara perangkat master dengan perangkat slave. Data serial dikirimkan dari perangkat master secara broadcast menuju perangkat slave dengan menggunakan modul komunikasi nirkabel APC220 yang berkerja pada frekuensi $433 \mathrm{MHz}$.

\section{KAJIAN LITERATUR}

\section{A. Jaringan Sensor Nirkabel}

Sebuah jaringan sensor nirkabel (JSN) adalah jaringan nirkabel yang terdiri dari perangkat otonom yang didistribusikan secara spasial menggunakan sensor untuk memantau kondisi fisik atau lingkungan. Sebuah sistem jaringan sensor nirkabel menggabungkan gateway yang menyediakan konektivitas nirkabel seperti halnya konektivitas kabel dan node terdistribusi seperti yang terlihat pada gambar 1. Pada gambar 1 terdapat beberapa sensor node dan satu gateway. Sensor node ini berfungsi sebagai pengumpul data yang berasal dari sensor yang dipasang pada node tersebut, yang kemudian akan mengirimkan data tersebut ke sebuah gateway yang akan mengirim kan data tersebut ke cloud/server. Gambaran ini akan menjadi dasar topologi sistem yang akan dibangun dalam penelitian ini. Protokol nirkabel dipilih sesuai dengan kebutuhan aplikasi yang dibangun [5].

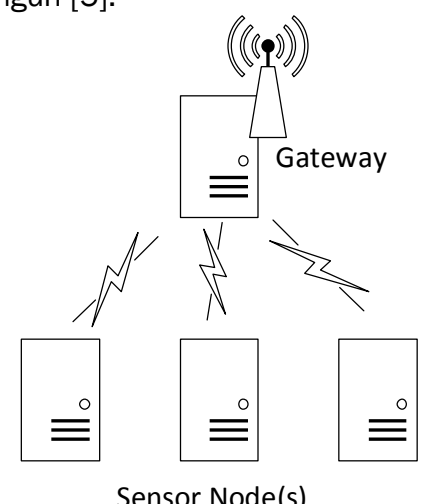

Gambar. 1 Komponen JSN, Gateway, dan Node

Beberapa fitur dari JSN antara lain sebagai berikut [6]:

- JSN vs Jaringan Ad-Hoc: JSN merupakan bagian dari jaringan ad-hoc dengan infrastruktur minim dan tipikal jaringan cooperation-based dimana topologi jaringan ditentukan oleh jaringan sensor itu sendiri.

- Posisi Sensor tidak Direkayasa maupun Didefinisikan: memungkinkan penyebaran sensor secara acak.

- Pengumpulan Data: node-node pada sensor memiliki kemampuan pengolahan sederhana.

- Homogen dan Heterogen: jaringan homogen apabila sensor-sensor memiliki kemampuan pengolahan dan komunikasi yang serupa. Sedangkan jaringan heterogen terjadi apabila sensor-sensor memiliki kemampuan pengolahan, komunikasi, atau bahkan baterai yang variatif.

- Sensor Dinamik vs Sensor Statik: JSN dapat dibagi menjadi dua kelompok; statik dan dinamik. Pada jaringan statik, sensor disusun pada posisi tetap dan data dapat dikumpulkan dalam jangkauan tertentu. Sedangkan pada jaringan dinamik, sensor dapat menempel pada objek bergerak seperti binatang, kendaraan, atau manusia [7].

- Location-aware vs Location-unaware Sensor: node-node sensor dapat berupa sensor yang dipengaruhi lokasi maupun tidak. Sensor yang dipengaruhi lokasi mengetahui posisi diri pada jaringan menggunakan perangkat khusus seperti GPS.

- Single-hop vs Multi-hop Network: berdasarkan pada jumlah hop yang dilalui sensor. Pada jaringan single-hop, sensor langsung mengirimkan data yang telah ditangkap oleh sensor ke sentral penampung. Sedangkan pada multi-hop, sensor mengirimkan data yang telah ditangkap oleh sensor ke sentral melalui beberapa sensor (node) sekitarnya, seperti yang diilustrasikan pada gambar 2(a) dan 2(b). 


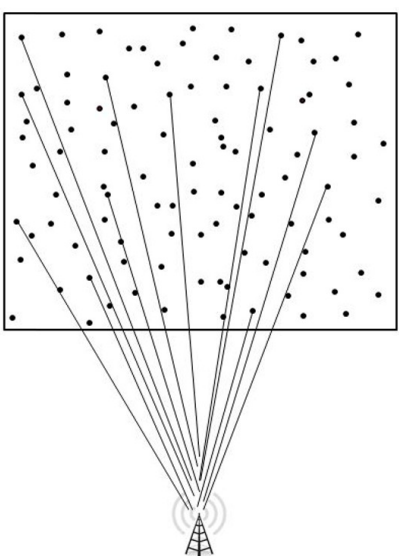

(a)

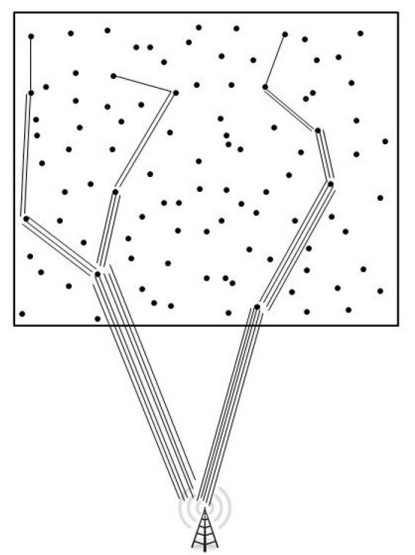

(b)

Gambar. 2 Perutean (a) Single-hop; (b) Multi-hop

- Skalabilitas: Algoritma skalabel dapat digunakan pada wide range untuk efisiensi JSN. Dari pengembangan sistem, jaringan single-hop lebih mudah dikembangkan daripada multi-hop. Hal ini dikarenakan jaringan multi-hop membutuhkan banyak node untuk dilalui sehingga berpotensi menghasilkan latensi yang juga besar [8], [9].

\section{B. Modul Radio APC220}

APC220 merupakan modul komunikasi nirkabel serbaguna dengan daya rendah yang mudah untuk diintegrasikan dengan projek manapun yang membutuhkan link frekuensi radio. Modul ini cocok untuk aplikasi robotik yang membutuhkan kendali secara nirkabel. Modul ini dapat dikoneksikan ke mikrokontroler melalui antarmuka TTL (Transistor Transistor Logic) kemudian mengkoneksikan PC dengan modul APC220 lainnya melalui konverter TTL/USB seperti yang terdeskripsikan pada gambar 3 [10]. Didalam gambar ini, sistem yang dibangun menjadi dua bagian. Bagian pertama adalah bagian APC 220 yang terkoneksi langsung dengan PC, dapat dilihat pada gambar 3.a, dimana sistem tersebut akan disebut sebagai master, dan bagian kedua dimana APC 220 akan terkoneksi langsung dengan Mikrokontroler, dimana sistem tersebut akan disebut sebagai slave.

(https://www.dfrobot.com/wiki/index.php/APC220 Radio Data Module(SKU:TELO005)

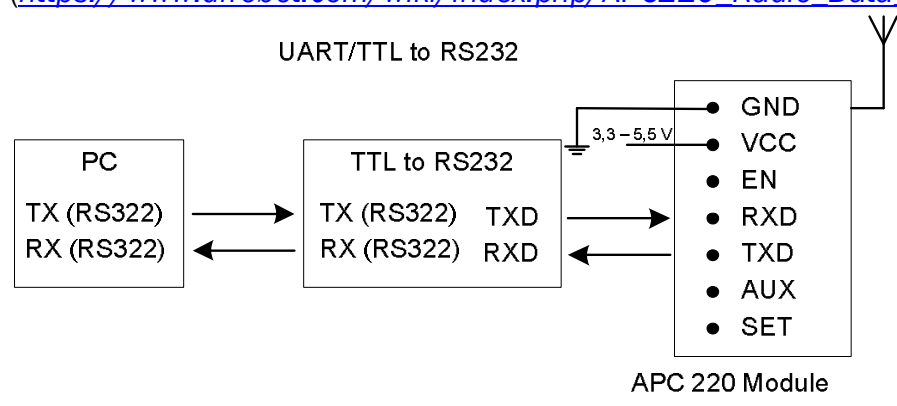

(a)

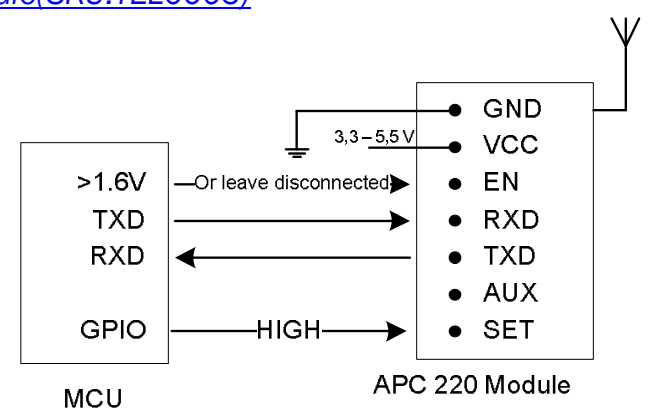

(b)

Gambar. 3 (a) Koneksi APC220 ke PC via Konverter RS232-TTL; (b) Koneksi APC220 ke MCU (Mikrokontroler)

Modul radio ini menggunakan GFSK (Gaussian Frequency Shift Keying) sebagai teknik modulasinya [11]. Modul komunikasi lain yang menggunakan GFSK sebagai teknik modulasinya antara lain Bluetooth ${ }^{\circledR}$ dan wireless USB. Tipe modulasi ini, pulsa baseband melalui Gaussian Filter terlebih dahulu sebelum dimodulasikan secara Frequency Shift Keying (FSK). Hal ini memungkinkan terjadinya efisiensi konservasi bandwidth ketika komunikasi digital terjadi [12].

Spesifikasi dari modul APC220 ini adalah sebagai berikut (secara detil terinci pada gambar 4):

- $\quad$ Frekuensi kerja antara 420MHz sampai dengan $450 \mathrm{MHz}$

- Tegangan: 3.5 VDC sa,,pai dengan 5.5VDC

- $\quad$ Arus: <25mA sampai dengan $35 \mathrm{~mA}$ 
- Jangkauan: $1200 \mathrm{~m}$ LOS (Line Of Sight)

- Antarmuka: UART/TTL

- Baudrate: 1200 bps sampai dengan 19200bps
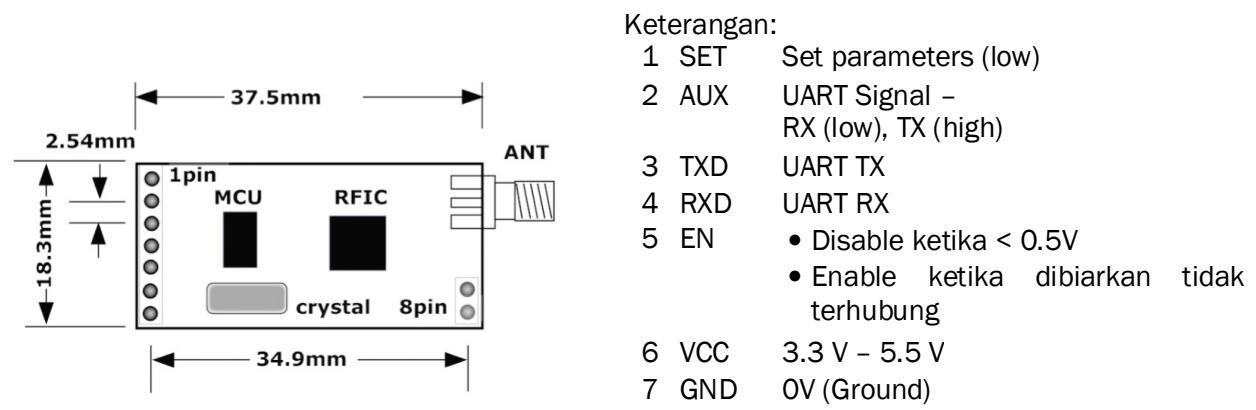

Gambar. 4 Pin Konfigurasi Modul APC220

\section{Pemodelan Sistem}

Sistem ini secara keseluruhan terdiri dari bagian perangkat master dan slave. Perangkat master bertindak sebagai pemberi perintah kepada perangkat slave. Perintah dari perangkat master berasal dari pengguna yang menginputkan (dengan memilih) salah satu lagu dalam playlist yang disajikan pada tampilan antarmuka pengguna yang terhubung dengan PC hingga menghasilkan deretan data serial. Perangkat slave menerima deretan data serial dari perangkat master tersebut untuk didekodekan hingga perangkat mekanik menggerakkan masing-masing angklung yang dimaksud.

Angklung yang digunakan pada penelitian ini terdiri dari dua unit Angklung Melodi Sarinande yang dibuat oleh Saung Udjo. Kedua unit angklung ini memainkan musik bersama-sama seperti kor pada paduan suara. Hal ini dimaksudkan untuk menambahkan volum suara pada ruangan pertunjukan sehingga tidak memerlukan sound system. Untuk menjalankan fungsi demikian, maka data serial dari perangkat master dikirim secara broadcast menuju perangkat slave. Mengingat ruangan pertunjukan cukup luas untuk menempatkan dua unit angklung ini maka komunikasi nirkabel antara perangkat master dan perangkat slave digunakan untuk mendukung sistem tersebut. Perangkat pendukung komunikasi nirkabel ini menggunakan APC220 yang bekerja pada frekuensi 433 MHz dengan jangkauan sekitar 1000 meter dalam kondisi LOS (line of sight) sehingga cukup untuk mencakup jangkauan 5 meter dalam kondisi NLOS.
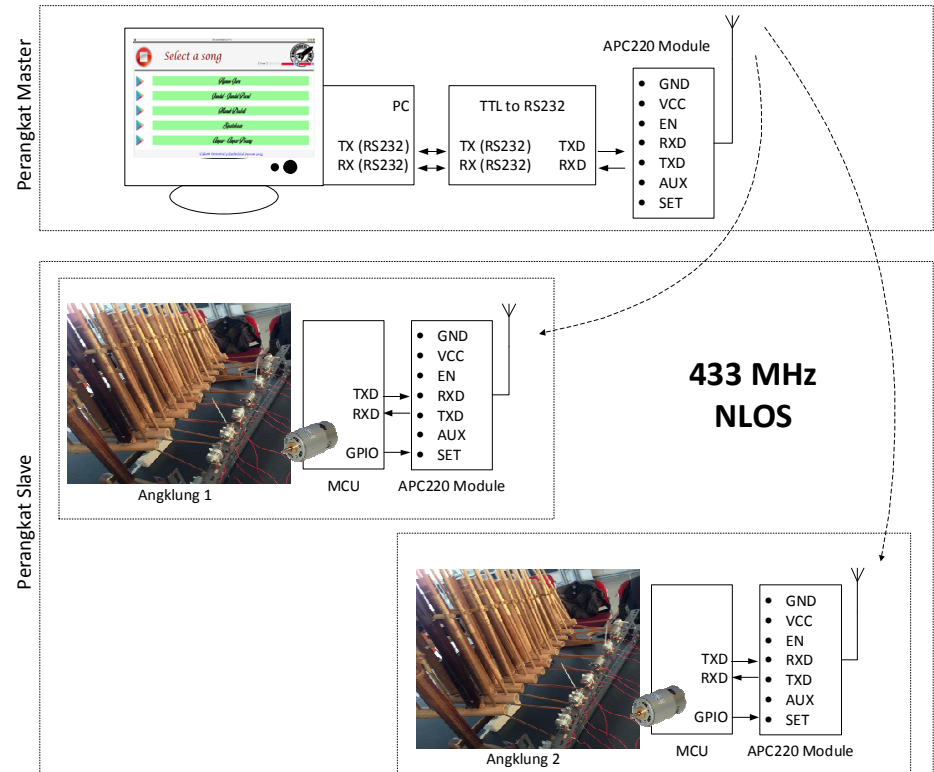

Gambar. 5 Pemodelan Sistem Robot Musik Angklung dengan Komunikasi Nirkabel 433 MHz 


\section{HASIL DAN PEMBAHASAN}

Terdapat lima pilihan lagu sekaligus tombol aksi "play" untuk memainkan lagu dan satu tombol aksi "stop" untuk menghentikan lagu pada tampilan menu antarmuka pengguna robot musik angklung ini, ketika salah satu lagu dipilih kemudian pengguna meng-klik "play" maka angklung akan memainkan lagu. Dan ketika pengguna memilih atau mengklik tombol "stop" maka angklung akan berhenti memainkan lagu. Tombol "stop" akan menginterupsi mekanik untuk menghentikan angklung kapan pun tombol ini ditekan. Skema kerja sistem ini terinci pada diagram alir gambar 6.

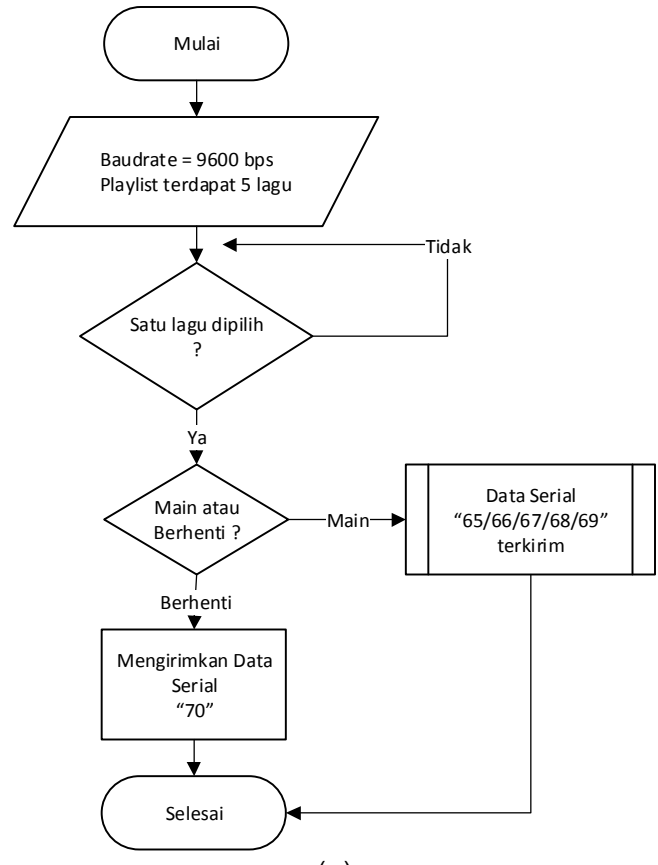

(a)

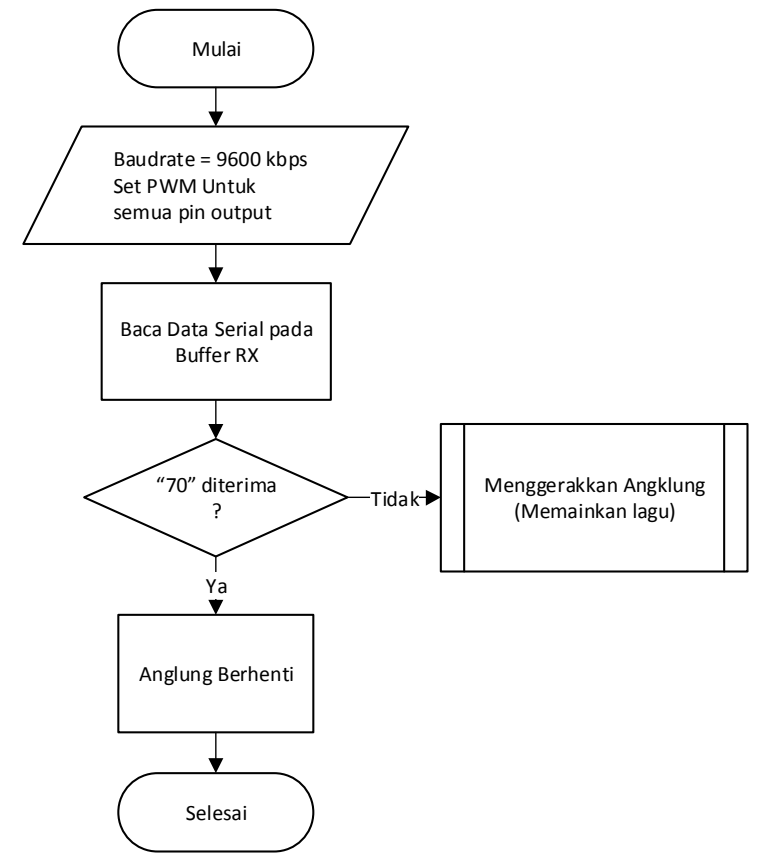

(b)

Gambar. 6 Diagram Alir Sistem pada (a) Perangkat Master; (b) Perangkat Slave

Masing-masing tombol diberi label berbeda untuk proses pengkodean yang selanjutnya dikirimkan dalam bentuk data serial. Pengkodean yang digunakan pada sistem ini terinci pada tabel 1 berikut:

TABEL I

PENGUJIAN FUnGSIONALITAS SISTEM

\begin{tabular}{|c|c|c|c|c|}
\hline \multirow[b]{2}{*}{ No } & \multicolumn{4}{|c|}{ Interaksi Perangkat Master dan Perangkat Slave } \\
\hline & $\begin{array}{l}\text { Perangkat Master } \\
\text { (Tombol Interaksi) }\end{array}$ & $\begin{array}{l}\text { Komunikasi } \\
\text { (Data Serial) }\end{array}$ & $\begin{array}{l}\text { Perangkat Slave } \\
\text { (Mekanik) }\end{array}$ & Keterangan \\
\hline 1 & $\begin{array}{l}\text { Hymne Guru - Sartono } \\
\text { (Play) }\end{array}$ & $65 d$ & Memainkan lagu Hymne Guru satu kali & Berhasil \\
\hline 2 & $\begin{array}{l}\text { Gundul-gundul Pacul - R.C. } \\
\text { Hardjosubroto } \\
\text { (Play) }\end{array}$ & $66 d$ & $\begin{array}{l}\text { Memainkan lagu Gundul-gundul Pacul } \\
\text { satu kali }\end{array}$ & Berhasil \\
\hline 3 & $\begin{array}{l}\text { Manuk Dadali - Sambas } \\
\text { Mangundikarta } \\
\text { (Play) }\end{array}$ & $67 d$ & $\begin{array}{l}\text { Memainkan lagu Manuk Dadali satu } \\
\text { kali }\end{array}$ & Berhasil \\
\hline 4 & $\begin{array}{l}\text { Si Patokaan - NN } \\
\text { (Play) }\end{array}$ & $68 d$ & Memainkan lagu Si Patokaan satu kali & Berhasil \\
\hline 5 & $\begin{array}{l}\text { Ampar-ampar Pisang - } \\
\text { Hamiedan AC } \\
\text { (Play) }\end{array}$ & $69 d$ & $\begin{array}{l}\text { Memainkan lagu Ampar-ampar Pisang } \\
\text { satu kali }\end{array}$ & Berhasil \\
\hline 6 & Stop & $70 d$ & Angklung berhenti & Berhasil \\
\hline 7 & Stop (ditengah lagu) & $70 d$ & Angklung berhenti di tengah lagu & Berhasil \\
\hline
\end{tabular}




\section{KeSIMPULAN}

Pembangunan sebuah sistem yang dapat menggetarkan Anklung layaknya seorang pemusik, dapat berjalan sesuai dengan design yang dirancang. Dalam komunikasi antara master dan slave, pengiriman data serial dengan menggunakan komunikasi nirkabel untuk pengiriman data pada robot musik angklung ini dapat diterapkan. Pengiriman data serial dari perangkat master berhasil didekodekan di kedua perangkat slave baik itu perintah untuk memainkan lagu maupun untuk memberhentikan lagu. Kedua perangkat slave dapat menggerakkan angklung-angklung dalam waktu bersamaan meskipun dalam jarak yang berjauhan pada ruang pertunjukan.

\section{REFERENSI}

[1] Hartono, “PENGEMBANGAN PARIWISATA MINAT KHUSUS KESENIAN TRADISIONAL," Jur. Seni Rupa, Fak. Bhs. dan Seni, Univ. Negeri Semarang, vol. Vol 1, No, 2005.

[2] T. Muhrizal Tanziilal and B. Dharmawan Putra, "Bentuk Penyajian Karya Musik Follow Me, Sebuah Karya Musik Pada Ujian Akhir Karya Musik Jurusan Sendratasik," Solah, vol. Vol 3, No , 2013.

[3] J. Yandika, D. Darjat, and A. A. Zahra, "PERANCANGAN SISTEM PENGIRIMAN DATA PEMILUKADA DIGITAL SECARA NIRKABEL DALAM LINGKUP TPS KE KECAMATAN MENGGUNAKAN ARF 7429B," TRANSIENT, vol. Vol. 3, No, no. Desember 2014, pp. 572 - 578, 2014.

[4] S. Nauvaliana, D. Darjat, and Y. Christiyono, "PERANCANGAN SISTEM PEMANTAUAN RUANGAN SECARA NIRKABEL MENGGUNAKAN ARF 7429B," TRANSIENT, vol. Vol. 2, No, no. September 2013, pp. 437 - 445, 2013.

[5] N. Instruments, “What Is Wireless Sensor Network?," White Papers, 2016. [Online]. Available: http://www.ni.com/white-paper/7142/en/. [Accessed: 20-Mar-2017].

[6] M. M. Zanjireh and H. Larijani, "A Survey on Centralised and Distributed Clustering Routing Algorithms for WSNs," IEEE 81st Veh. Technol. Conf. (VTC Spring), pp. 1 - 6, 2015.

[7] B. Liu and O. Dousse, "Dynamic Coverage of Mobile Sensor Networks," vol. 24, no. 2, pp. 301-311, 2013.

[8] I. F. Akyildiz, W. Su, Y. Sankarasubramaniam, and E. Cayirci, “A survey on sensor networks," IEEE Commun. Mag., vol. 40, no. 8, pp. 102-114, 2002.

[9] M. Ilyas and I. Mahgoub, Handbook of Sensor Networks: Compact Wireless and Wired Sensing Systems. Taylor \& Francis, 2004.

[10] DFRobot, “APC220 Radio Data Module (SKU:TELO005)," 2016. [Online]. Available: https://www.dfrobot.com/wiki/index.php/APC220_Radio_Data_Module(SKU:TEL0005). [Accessed: 20-Mar-2017].

[11] P. Overview, “APC Series Transparent Transceiver Module Product Overview: Application : Characters :," pp. 1-10.

[12] T. Švedek, M. Herceg, and T. M. Ć, "A Simple Signal Shaper for GMSK / GFSK and MSK Modulator Based on Sigma-Delta Look-up Table," RAdio Eng., vol. 18, no. 2, pp. 230-237, 2009. 